\title{
Violence against women before and during gestation: differences in prevalence rates and perpetrators
}

Marizélia Rodrigues Costa Ribeiro 1

https://orcid.org/0000-0003-4289-4527

Bianca Portela Teles Pessoa 2

https://orcid.org/0000-0002-9756-814X

Galvani Ascar Sauaia 3

https://orcid.org/0000-0002-8725-7428

Lilia Blima Schraiber 4

https://orcid.org/0000-0002-3326-0824
Rejane Christine de Sousa Queiroz 5

(iD) https://orcid.org/0000-0003-4019-2011

Rosângela Fernandes Lucena Batista 6

(iD) https://orcid.org/0000-0002-1529-0165

Joana Athayde da Silva Cruz 7

https://orcid.org/0000-0002-0038-3449

Antônio Augusto Moura da Silva 8

https://orcid.org/0000-0003-4968-5138

1-3 Departamento de Medicina III. Universidade Federal do Maranhão. Praça Gonçalves Dias, 21. Centro. São Luís, MA, Brasil. CEP: 65.020-240. Email: marizelia13@gmail.com

2 Secretaria de Saúde do Estado do Maranhão. UPA Itaqui Bacanga. São Luís, MA, Brasil.

4 Departamento de Medicina Preventiva.Faculdade de Medicina. Universidade de São Paulo. São Paulo, SP, Brasil.

5,6,8 Programa de Pós-Graduação em Saúde Coletiva. Universidade Federal do Maranhão. São Luís, MA, Brasil.

7 Secretaria Municipal de Saúde de Barreirinhas. Prefeitura Municipal de Barreirinhas. Barreirinhas, MA, Brasil.

\begin{abstract}
Objectives: to analyze differences in prevalence and perpetrators of violence against women before and during pregnancy.

Methods: this is a cross-sectional study with a sample of 1,446 pregnant women interviewed in 2010 and 2011 in the São Luis municipality (Brazil). Thirteen questions measured psychological, physical and sexual violence in the 12 months before and during pregnancy. Psychological/physical/sexual violence was defined as any type of violence perpetrated against the interviewees. The perpetrators were categorized into intimate partner, other family members, community members, and multiple perpetrators. Differences between violence before and during pregnancy were analyzed by the chi-square test.

Results: psychological/physical/sexual and psychological violence were more prevalent during pregnancy than before gestation $(p<0.001)$. Insults, humiliation and intimidation $(p<0.05)$ were more frequently reported during pregnancy. An intimate partner was the most frequent perpetrator. There were no differences in the percentage of moderate and severe forms of physical violence and sexual violence, recurrence of aggressions and perpetrators in both periods ( $p>0.05)$.

Conclusions: gestation did not protect users of prenatal services in São Luís municipality from psychological, physical and sexual violence. Psychological/physical/sexual and psychological violence were more commonly practiced during pregnancy. The perpetrators of violence in the year before gestation continued to abuse the interviewees during pregnancy Key words Gender-based violence, Intimate partner violence, Pregnancy, Violence against women
\end{abstract}




\section{Introduction}

Violence against women is considered a public health problem and a human rights violation because they may be a threat to the lives, health and development of women and their children.1,2 It has been defined by the Inter-American Conventionas any threat or act of gender-based violence that causes or appears to result in physical, sexual or psychological harm or suffering to the woman, whether it occurs in the family environment or at other public spaces. 3

It is estimated that up to $59 \%$ of women from different socioeconomic status and cultures will be subjected to violence at least once in their lives, ${ }^{4}$ including during pregnancy, when women are expected to minimally expose themselves to risks that could compromise maternal and child health.Results from the WHO Multi-Country Study on Women's Health and Domestic Violence against Women (WHO VAW) showed that violence against pregnant women ranged from $1 \%$ in Japan to $28 \%$ in a province in Peru. In Brazil, the prevalence of physical violence was $8 \%$ in the city of São Paulo (South region of Brazil) and $11 \%$ in the Zona da Mata, a region of Pernambuco State (Northeast region of Brazil). 5

Violence during pregnancy is often a continuation of past maltreatment.6-13 It is not clear whether gestation would protect women from violence or its types.6,7,9,10 Among nine articles analyzed in a systematic review, the aggressions suffered before gestation continued in $31.3 \%$ to $69.2 \%$ of the cases and ceased in $30.8 \%$ to $68.7 \%$ of them. 6 Two Brazilian studies showed that the chance of violence by an intimate partner occurring during pregnancy was more than 11 times higher when there were reports of maltreatment in the 12 months precedinggestation. ${ }^{12,13}$ Another study that interviewed women during the postpartum period in the Brazilian cities of São Paulo and Recife (State of Pernambuco) observed a decrease of physical violence during pregnancy in both cities, an increase in psychological violence in the city of Recife, and similar rates of sexual violence in both locations. ${ }^{14}$

Psychological, physical and sexual violence practiced against pregnant women usually has as its main perpetrator a current or former intimate partner. 1,6,10,14 Other subjects of the domestic environment, people who are in contact with the pregnant woman in other social environments and unacquainted subjects are still little investigated as perpetrators of violence. 6

This study had the following hypotheses: a) pregnancy does not protect women from violence; $b$ ) perpetrators of violence in the 12 months prior to gestation continue to abuse women when they are pregnant. Therefore, the purpose of this study was to analyze differences between prevalence rates of psychological/physical/sexual (any type of violence), psychological, physical and sexual violence before and during gestation, and differences among perpetrators of psychological/physical/sexual violence. It innovates when compared to other Brazilian studies because it tests differences in the forms and severity of the episodes and it analyzes differences among perpetrators of violence before and during pregnancy.

\section{Methods}

The data used in this cross-sectional study were collected from the database of the Brazilian Ribeirão Preto and São Luís Birth Cohort Studies (BRISA) regarding the city of São Luís. São Luís, capital of the state of Maranhão, is part of the Northeast region of Brazil. It had a population of 1,014,837 inhabitants and a Human Development Index (HDI) of 0.768 in 2010.15 In 2011 , only $41.4 \%$ of pregnant women attended seven or more prenatal visits. 16

A convenience sample was used because of the difficulty in obtaining a random sample of the pregnant women population. Pregnant women were recruited while waiting for prenatal care appointments at the three largest public maternity hospitals and in ultrasound clinics. Inclusion criteria were having the first obstetric ultrasound performed in the first 20 weeks of gestation, single gestation and intention to give birth in São Luís. An interview took place from the $22^{\text {th }}$ to the $25^{\text {th }}$ week of pregnancy at the Clinical Research Center of the Federal University of Maranhão. The final sample of BRISA São Luís prenatal cohort consisted of 1,447 women.

Data on violence in BRISA cohort were collected through a self-applied instrument. Demographic, socioeconomic and behavioral characteristics were obtained by trained interviewers. The data collection period went from February 2010 to June 2011.

The thirteen questions that measured violence during gestation and in the previous twelve months were obtained from the Brazilian version of the World Health Organization Violence Against Women (WHO VAW). 17 This instrument was validated in Brazil by the WHO VAW study and for pregnant women. $18,19 \mathrm{Psychological} / \mathrm{physical} / \mathrm{sexual}$ violence was considered as the sum of episodes of psychological, physical or sexual violence.

Four questions that measured psychological 
violence were as follows: a) "Insult you or made you feel bad about yourself?"; b) "Depreciate or humiliate you in front of other people?"; c) "Do things to scare or frighten you on purpose (e.g., the way he/she looks at you, how he/she screams, breaks things)?"; and d) "Threaten to hurt you or someone you care about?". 17 Insults and humiliations were classified as moderate psychological violence and the other forms of violence as severe.

Six items that addressed physical violence were: a) "Slap you or throw something at you that could hurt you?"; b) "Push you or give you a shake?"; c) "Punch you or hurt you with any object?"; d) "Kick you, drag you or beat you?"; e) "Attempt to strangle or burn you on purpose?"; and f) "Threaten to use or actually used a firearm, knife or other weapon against you?". ${ }^{17}$ Slaps, throwing objects, shoving and shaking were classified as moderate physical violence and the other forms of violence as severe. 20

To measure sexual violence, the following questions were asked: a) "Did this person physically force you to have sex when you did not want to?"; b) "Did you have sexual intercourse because you were afraid of what this person could do?"; and c) "Did this person force you into a sexual practice that you consider humiliating?".17

The answer options were: a) no; b) once; c) a few times; and d) many times. It was considered that violence was recurrent when the response was "a few times" or "many times".17

The perpetrators were classified into: a) intimate partner; b) other family members; c) community members; and d) multiple subjects. Women who did not identify the perpetrators either because they did not want to or because they pointed out that "there was no violence" were excluded from the analysis.

To characterize pregnant women the followingvariables were used: age of the pregnant woman (categories up to 19 years, 20 to 24 years or 25 years or more), marital status (categorized as marriage, consensual union, single/widowed and divorced/ separated), schooling (categorized in up to 4 years, 5 to 8 years, 9 to 11 years and 12 years or over), head of household (categorized into the pregnant woman herself, intimate partner and others), and economic class (categorized into $\mathrm{D} / \mathrm{E}, \mathrm{C}$ and $\mathrm{A} / \mathrm{B}$ ).

The instrument to define the economic class used was created by the Associação Brasileira de Empresas de Pesquisas (Brazilian Association of Survey Companies). The "Brasil" criterion of economic classification established the social classes A, B, C, D and E according to whether the family owns certain assets and to the head of the family's degree of education, with categories A and B implying the highest purchasing power and schooling. ${ }^{21}$

All variables were investigated as categorical. The descriptive analysis of the data for characterization of the sample was carried out through absolute frequencies, percentages and central tendency measures. Differences between prevalence rates of violence before and during the gestational period were considered to exist when $p<0.05$ by the chisquare test. The statistical analysis was performed using the STATA software, version 10.0.

This study was approved by the Research Ethics Committee of the University Hospital of the Federal University of Maranhão (Comitê de Ética em Pesquisa do Hospital Universitário da Universidade Federal do Maranhão - HUUFMA), according to approval number $223 / 2009$. The subjects signed a Free and Informed Consent Form, in accordance with the norms regulating research involving human beings, in compliance with resolution 196/1996 of the National Health Council (Conselho Nacional de Saúde).

\section{Results}

One pregnant woman was excluded because she did not answer violence related questions. Thus, the final sample for analysis totalled 1,446.

Around $12 \%$ of them were up to 19 years old and $58 \%$ lived in consensual union. The pregnant woman was head of the family in only $10.8 \%$ of the households. About 75\% counted between 9 and 11 schooling years and $67 \%$ belonged to economic class C (Table 1). Only three pregnant women had never attended school (data not shown in table).

Psychological/physical/sexual violence was more frequent $(p<0.001)$ during gestation $(49.7 \%)$ than in the 12 months preceding it (38.3\%) (Table 2).

Psychological violence was also more frequent $(p<0.001)$ during pregnancy $(48.4 \%)$ than in the 12 months before gestation $(36.4 \%)$, with insults $(p<0.001)$, humiliations $(p=0.01)$ and bullying $(p<0.001)$ being reported more frequently during pregnancy than before it. Prevalence rates of recurrent psychological violence were similar in both periods $(p=0.436)$. The first episode of psychological violence occurred during pregnancy for $35.3 \%$ of the interviewees (Table 2).

Regarding physical (Table 3) and sexual violence (Table 4), there were no significant differences between prevalence rates, types of aggression, severity of physical violence and recurrence of episodes before and during gestation. The first episode of physical violence occurred during preg- 
Demographic factors and socioeconomic status of the 1,446 prenatal service users. São Luís prenatal cohort, Brazil, 2010-2011.

\begin{tabular}{lcc}
\hline Pregnant women characteristics & N & $\%$ \\
\hline Age (years) $(n=1,446)$ & & \\
Up to 19 & 178 & 12.3 \\
20 to 24 & 476 & 32.9 \\
25 or more & 792 & 54.8 \\
Marital status ( $n=1,446)$ & 329 & 22.7 \\
Married & 831 & 57.5 \\
Consensual union & 263 & 18.2 \\
Single/widowed & 23 & 1.6 \\
Divorced/separated & & \\
Head of the familya ( $n=1,442)$ & 156 & 10.8 \\
Pregnant woman & 846 & 58.7 \\
Intimate partner & 440 & 30.5 \\
Others & & \\
Schooling (years)a ( $n=1,445)$ & 21 & 1.5 \\
0 to 4 & 162 & 71.2 \\
5 to 8 & 1,090 & 11.9 \\
9 to 11 & 172 & \\
12 or more & & 16.3 \\
Economic class "Brasil"a criterion ( $n=1,379)$ & 225 & 67.7 \\
D/E & 933 & 16.0 \\
C & 221 & \\
A/B & & \\
\hline
\end{tabular}

a Missing values were excluded.

nancy for $46.9 \%$ of the women (Table 3 ). About $48 \%$ of pregnant women who suffered sexual violence reported the first episode during gestation (Table 4).

There were no differences regarding the perpetrators in both periods (Table 5). Thirty-seven pregnant women who suffered psychological abuse did not identify the author(s) because they considered that there had been no psychological violence (data not shown in table).

\section{Discussion}

Psychological/physical/sexual and psychological violence were more frequent during pregnancy than in the 12 months preceding gestation. Insults, humiliation and intimidation, that were forms of psychological violence, were more frequent during pregnancy. Recurrence of psychological violence was similar in the two periods investigated. Episodes of psychological violence had more often started before gestation. Prevalence rates and recurrences of physical and sexual violence were similar before and during pregnancy. The first episode of physical aggression and sexual abuse occurred during gesta- tion for almost half of the interviewees submitted to these two types of violence. There were no differences between perpetrators of psychological/physical/sexual violence practiced before and during pregnancy.

One possible limitation of this study is memory bias, especially regarding violence occurring before gestation, isolated episodes as well as less severe forms of psychological violence. It is possible that because the interviewees were informed that the BRISA study aimed to study the etiology of preterm birth, with violence as one of the investigated causes, there could have been an effort to recall episodes that occurred during pregnancy. The fact that the study used a convenience sample limits the external generalization of the findings.

Psychological/physical/sexual violence largely reflected psychological violence, the most common 5 and present type for almost all pregnant women who had undergone maltreatment in BRISA São Luís prenatal cohort. It should be noted that the psychological violence began during pregnancy for about $35 \%$ of women, showing that for most of the interviewees, violence was just a continuation of aggres- 
Table 2

Psychological/physical/sexual and psychological violence according to the frequence of episodes in the 12 months preceding gestation and during gestation. São Luís prenatal cohort, Brazil, 2010-2011.

\begin{tabular}{|c|c|c|c|c|c|}
\hline \multirow[t]{2}{*}{ Variables } & \multicolumn{2}{|c|}{ Violence before gestation } & \multicolumn{2}{|c|}{ Violence during gestation } & \multirow[t]{2}{*}{$p$} \\
\hline & $\mathrm{n}$ & $\%$ & $\mathrm{n}$ & $\%$ & \\
\hline Psychological/physical/sexual violence & & & & & $<0.001$ \\
\hline No & 892 & 61.7 & 726 & 50.3 & \\
\hline Yes & 554 & 38.3 & 716 & 49.7 & \\
\hline Psychological violence & & & & & $<0.001$ \\
\hline No & 920 & 63.6 & 746 & 51.6 & \\
\hline Yes & 526 & 36.4 & 700 & 48.4 & \\
\hline V1) "Insult you or made you feel bad about yourself?" & & & & & $<0.001$ \\
\hline No & 1,034 & 71.5 & 895 & 61.9 & \\
\hline Yes & 412 & 28.5 & 551 & 38.1 & \\
\hline V2) "Depreciate or humiliate you in front of other people?" & & & & & 0.010 \\
\hline No & 1,180 & 81.6 & 1,129 & 78.1 & \\
\hline Yes & 266 & 18.4 & 317 & 21.9 & \\
\hline V3) "Do things to scare you or frighten you on?" & & & & & $<0.001$ \\
\hline No & 1,222 & 84.5 & 1,123 & 77.7 & \\
\hline Yes & 224 & 15.5 & 323 & 22.3 & \\
\hline No & 1,302 & 90.1 & 1,274 & 88.1 & \\
\hline Yes & 144 & 9.9 & 172 & 11.9 & \\
\hline Recurrent psychological violence & & & & & 0.436 \\
\hline 1 episode & 146 & 10.1 & 184 & 12.7 & \\
\hline Recurrent & 380 & 26.3 & 516 & 35.7 & \\
\hline Total & 526 & 36.4 & 700 & 48.4 & \\
\hline Psychological violence initiated during gestation & & & 247 & $35.3 a$ & \\
\hline
\end{tabular}

a Percentage calculated from the total of women who suffered psychological violence. 
Physical violence according to the frequency of episodes in the 12 months preceding gestation and during gestation. São Luís prenatal cohort, Brazil, 2010-2011.

Violence before gestation Violence during gestation

Physical violence

No

Yes

V5) "Slap you or throw something at you that could hurt you?"

No

Yes

V6) "Push you or give you a shake?"a

No

Yes

V7) "Punch you or hurt youwith any object?" a

No

Yes

V8) "Kick you, drag you or beat you?"b

No

Yes

V9) "Attempt to strangle or burn you on purpose?" b

No

Yes

V10) "Threaten to use or actually used a firearm, knife or other weapon against you?"b No

Yes

Total

Recurrent physical violence

1 episode

Recurrent

Total

Physical violence initiated during gestation

\begin{tabular}{|c|c|c|c|}
\hline \multicolumn{2}{|c|}{ Violence before gestation } & \multicolumn{2}{|c|}{ Violence during gestatior } \\
\hline $\mathrm{n}$ & $\%$ & $\mathrm{n}$ & $\%$ \\
\hline 1,275 & 88.2 & 1,264 & 88. \\
\hline 171 & 11.8 & 179 & 12. \\
\hline 1,353 & 93.6 & 1,356 & 93. \\
\hline 93 & 6.4 & 90 & 6.2 \\
\hline 1,351 & 93.4 & 1,329 & 92. \\
\hline 95 & 6.6 & 116 & 8.0 \\
\hline 1,404 & 97.1 & 1,403 & 97. \\
\hline 42 & 2.9 & 42 & 2.9 \\
\hline 1,410 & 97.5 & 1,413 & 97. \\
\hline 36 & 2.5 & 33 & 2.3 \\
\hline 1,431 & 99.0 & 1,437 & 99. \\
\hline 15 & 1.0 & 9 & 0.6 \\
\hline & & & \\
\hline 1,418 & 98.1 & 1,421 & 9.3 \\
\hline 28 & 1.9 & 24 & 1.7 \\
\hline 1,446 & & 1,445 & \\
\hline
\end{tabular}

88.6

12.4

93.8

92.0

97.1

97.7

2.3

99.4

0.6

9.3

1.7

$\begin{array}{cccc}89 & 6.1 & 96 & 6.6 \\ 82 & 5.6 & 83 & 5.7 \\ 171 & 1.7 & 171 & 1.3 \\ & & 84 & 46.9 c\end{array}$

0.337

0.439

0.076

0.543

0.404

0.153

0.338

0.512

a Moderate physical violence; b Severe physical violence; c Percentage calculated from the total of women who suffered physical violence. 
Table 4

Sexual violence according to the frequency of episodes in the 12 months preceding gestation and during gestation. SãoLuís prenatal cohort, Brazil, $2010-2011$.

Variables Violence before gestation Violence during gestation

\begin{tabular}{|c|c|c|c|c|c|}
\hline & & & & & \\
\hline & $\mathrm{n}$ & $\%$ & $\mathrm{n}$ & $\%$ & \\
\hline Sexual violence & & & & & 0.409 \\
\hline No & 1,408 & 97.4 & 1,404 & 97.2 & \\
\hline Yes & 38 & 2.6 & 41 & 2.8 & \\
\hline No & 1,424 & 98.5 & 1,421 & 98.3 & \\
\hline Yes & 22 & 1.5 & 24 & 1.7 & \\
\hline V12) "Did you have sexual intercourse because you were afraid of what this person could do?" & & & & & 0.443 \\
\hline Yes & 26 & 1.8 & 24 & 1.7 & \\
\hline V13) "Did this person force you into a sexual practice that you consider humiliating?" & & & & & 0.500 \\
\hline No & 1,426 & 98.6 & 1,427 & 98.7 & \\
\hline Yes & 20 & 1.4 & 19 & 1.3 & \\
\hline Total & 1,446 & & 1,445 & & \\
\hline Recurrent sexual violence & & & & & 0.303 \\
\hline 1 episode & 16 & 1.1 & 23 & 1.6 & \\
\hline Sexual violence initiated during gestation & & & 20 & $48.4 \mathrm{a}$ & \\
\hline
\end{tabular}

a Percentage calculated from the total of women who suffered sexual violence. 
Perpetrators of psychological/physical/sexual violence against pregnant women in the 12 months preceding gestation and during gestation. São Luís prenatal cohort, Brazil, 2010-2011.

\begin{tabular}{lccccc}
\hline Perpetrators & \multicolumn{2}{c}{ Violence before gestation } & Violence during gestation & \multicolumn{1}{c}{$\boldsymbol{p}$} \\
\cline { 2 - 5 } & $\mathrm{n}$ & $\%$ & $\mathrm{n}$ & $\%$ & \\
\hline Intimate partner & 191 & 48.8 & 180 & 46.0 & 0.342 \\
Other family members & 100 & 25.6 & 110 & 28.1 & 0.296 \\
Community members & 45 & 11.5 & 37 & 0.235 \\
Multiple perpetrators & 55 & 14.1 & 64 & 16.4 & 0.251 \\
Total & 391 & 100.0 & 391 & 100.0 & 0.520 \\
\hline
\end{tabular}

sions that started before gestation. Nine studies analyzed in a review showed that maltreatment of pregnant women was initiated before pregnancy for at least $60 \%$ of the interviewees, which is in line with our evidence. 6

Although gestation is considered a physiological process in the life of women of reproductive age, it is a period characterized by physical and psychological changes, family socioeconomic reorganizations and changes in life projects and interpersonal relationships, which can foment conflicts, especially in domestic environment and at work. ${ }^{22}$ Such conflicts themselves would not trigger violence if they were not somewhat allowed by traditional gender norms historically present in societies of different socioeconomic conditions and cultures, which place women in a social position that is hierarchically inferior to that of men, and therefore tolerate genderbased violence. In this perspective, not having planned pregnancy with the partner, getting pregnant without family approval, not having financial independence, doubts about paternity and decreased sexual desire by the woman, among other factors, may be associated with violence against pregnant women.6,13,23

As in the BRISA São Luís prenatal cohort, three other Brazilian studies also compared psychological violence perpetrated against women before and during pregnancy. 12-14 In "Grande Florianópolis" (a metropolitan agglomeration of the municipalities around the main city of Florianópolis, South region of Brazil), the chance of experiencing psychological violence by an intimate partner during pregnancy increased by approximately 12 times for women with reports of psychological maltreatment in the year preceding pregnancy. 12 Results of a study with women in postpartum period from a health district in the city of Recife showed an increase in psychological violence during pregnancy compared to the previous 12 months. 13 Another study with women during the puerperal period from the city of São Paulo did not find differences in the percentage of psychological violence practiced before and during gestation. 14

A review about violence against pregnant womencited studies that showed continuity of prior psychological violence during gestation. ${ }^{6}$ A study of 426 postpartum women in Bangladesh found a reduction in psychological violence during gestation compared to the pre-pregnancy period. 7 The risk of psychological maltreatment for Slovene puerperal women increased 3.3 times when there was a history of psychological violence in adulthood. 8

In the BRISA São Luís prenatal cohort, there were no differences in the percentage of recurrence of psychological violence in the two periods investigated. Studies analyzed in a review about violence against pregnant women showed that recurrence of episodes occurred both before and during gestation. 6

Insults and humiliation, episodes considered of moderate severity, and intimidation, a severe episode, were more frequent during pregnancy than in the previous 12 months. Only for the item "Did this person threaten to hurt you or someone you like", also considered severe, no differences were found between the two periods $(p=0.054)$.

The study conducted in Florianópolis did not test differences between episodes of violence before and during gestation. Prevalence rates of insults (15.5\%), humiliation $(4.3 \%)$, intimidation $(3.9 \%)$ and threats of physical violence against pregnant women $(2.1 \%)$ in this municipality 12 were more than twice lower than those found in the BRISA São Luís prenatal cohort.

In the sample studied, the first episode of physical and sexual violence occurred during gestation for almost half of the women submitted to these two types of aggressions, showing that being pregnant did not protect the woman from physical and sexual maltreatment. Going through the first episode of 
violence during gestation was considered a rare phenomenon in a Slovene study with 1,269 women. Among the studied Slovenian women, only $2 \%$ and $0.7 \%$ suffered their first episode of, respectively, psychological and physical violence during pregnancy. No sexual violence was observed during gestation. 8

There was no difference in the percentage of physical and sexual violence regarding prevalence rates, episodes, recurrence and severity of episodes before and during pregnancy in the BRISA São Luís prenatal cohort.

A North American study of 3,543 postpartum women also found no difference between physical rates before and during pregnancy. ${ }^{11}$ In Recife, physical intimate partner violence decrease nearly 50\% in the pregnancy when compared to the 12 months preceding it. However, it did not identify differences in the frequency of episodes of sexual abuse before and during gestation. ${ }^{13}$ In Bangladesh, there was a reduction in the frequency of episodes of both physical and sexual abuse during pregnncy. 4 A Slovenian study pointed to a 2.3 -fold greater risk of physical violence during gestation when there was a history of previous maltreatment in adulthood and an even greater 5.6-fold risk of sexual violence. 8

In the BRISA São Luís prenatal cohort, moderate episodes of physical violence before and during pregnancy were more frequent than severe episodes. Slapping and pushing occurred for about $6 \%$ to $12 \%$ of respondents and episodes of punching, kicking, strangling, burns and threats of use of knives and guns ranged from approximately $0.6 \%$ to $3 \%$.

A Peruvian study also found a higher frequency of moderate physical violence, such as slapping and pushing, than severe physical violence, both before and during pregnancy. ${ }^{9}$ Among users of public health services in Metropolitan São Paulo, episodes of moderate psychological and physical violence were more frequent than severe violence. ${ }^{20} \mathrm{~A}$ review of violence during gestation indicated that moderate violence appears to increase during pregnancy with a reduction in severe episodes. ${ }^{6}$

Recurrence of physical and sexual violence occurred for about half of the women subjected to maltreatment in these forms. This finding is compatible with the recurrence rate found in Metropolitan São Paulo, where $55.5 \%$ of the pregnant women interviewed had been maltreated by their relatives on more than one occasion. 20 In Recife, women who reported violence during pregnancy presented higher rates of violence during puerperium than those who did not report violence during gestation. 13 These results indicate a pattern of recurrence and conti- nuity of violence. 13,20

The most frequent perpetrator of violence in the present study was a current or former intimate partner, both before and during pregnancy, followed by family members. The results indicated that the perpetrators of violence in the previous 12 months remain as perpetrators during gestation.

National and international scientific literature point out people from the family environment as the main perpetrators of maltreatment of pregnant women, 6,14 highlighting a current or former intimate partner. 6,9,10,13,14,23 An American study that analyzed physical violence against pregnant women identified several different perpetrators. Most frequently, it was a current or former partner/husband, followed by family members, multiple subjects, friends and other perpetrators. There was a similarity between who was the perpetrator before and during gestation. ${ }^{11}$

Finally, the results reinforce the need for prenatal care professionals in the city of São Luís to identify pregnant women in situations of violence and to guide them to seek help in the municipal coping network, which has the Brazilian Women's House (Casa da Mulher Brasileira), a service center specializing in the care of women in situations of violence. It is not uncommon for primary care health professionals, where the vast majority of prenatal care for the Brazilian population takes place, to be unaware of violence against women as a matter of public health, violation of human rights and that this matter is in the scope of their work.24,25 The frequency and recurrence of episodes before and during pregnancy and the onset of violence during gestation in the prenatal cohort BRISA São Luís showed that violence against pregnant women is more frequent than diseases frequently investigated in prenatal consultations, i.e. gestational diabetes. ${ }^{26}$

This study has three points considered to be strengths. First, it used the WHO VAW questionnaire, which investigates violence in psychological, physical and sexual forms, having its psychometric characteristics analyzed and being validated for the study sample. Second, it applied the instrument to measure violence in a self-administered way, which reduced the chances of concealing episodes of maltreatment and the identity of the perpetrators. Third, the study analyzes the different forms of violence episodically and compares authors in both periods.

This study showed that gestation did not protect users of prenatal services in the city of São Luís from violence or its psychological, physical and sexual forms. Psychological/physical/sexual and psychological violence were more commonly prac- 
ticed during pregnancy, when compared to a 12 month prior period. The perpetrators of violence in the year before gestation continued to abuse the interviewees during pregnancy. These results reinforce the need to investigate violence during gestation.

\section{Acknowledgments}

The authors wish to thank the women who kindly agreed to participate in the BRISA investigation, as well as the interviewers, without whose help the data could not have been collected.

\section{Funding Information}

This research was supported by grants from the Brazilian National Research Council (Conselho Nacional de Desenvolvimento Cientifico $e$ Tecnológico); and from the Maranhão Research and Scientific Development Foundation (Fundação de Amparo à Pesquisa e ao Desenvolvimento Científico e Tecnológico do Maranhão).

\section{Author's contribution}

Ribeiro MRC, Pessoa BPT, Schraiber LB, Queiroz RCS, Batista RFL and Silva AAM: substantial contributions to conception and design, acquisition of data, analysis and interpretation of data, drafting the article. Sauaia GA and Cruz JAS: substantial contributions to analysis and interpretation of data; drafting the article. All authors approved the final version to be published.

\section{References}

1. WHO (World Health Organization). Global and regional estimates of violence against women: prevalence and health effects of intimate partner violence and non-partner sexual violence. Geneva; 2013.

2. Day T, McKenna K, Bowlus A. The economic costs of violence against women: an evaluation of the literature. New York: United Nations; 2005.

3. Organization of American States. Inter-American convention on the prevention, punishment, and eradication of violence against women. Washington: OAS; 1994.

4. United Nations. The World's Women 2010: trends and statistics. New York: UN; 2010.

5. WHO (World Health Organization). WHO multi-country study on women's health and domestic violence against women: initial results on prevalence, health outcomes and women's responses. Geneva; 2005.

6. Taillieu TL, Brownridge DA. Violence against pregnant women: prevalence, patterns, risk factors, theories, and directions for future research. Aggression Violent Behavior. 2010; 15 (1): 14-35.

7. Islam MJ, Broidy L, Mazerolle P, Baird K, Mazumder N Exploring intimate partner violence before, during, and after pregnancy in Bangladesh. J Interpers Violence. 2018; 00 (0): 1-29.

8. Velikonja VG, Lučovnik M, Sršen TP, Leskošek V, Krajnc M, Pavše L, Blickstein I. Violence before pregnancy and the risk of violence during pregnancy. Journal of perinatal medicine. 2018; 46 (1): 29-33.

9. Perales, MT, Cripev SM, Lam N, Sanchez SE, Sanchez E,
Williams MA. Prevalence, types, and pattern of intimate partner violence among pregnant women in Lima, Peru. Violence AgainstWomen. 2009; 15 (2): 224-50.

10. Castro R, Peek-Asa C, Ruiz A. Violence Against Women in Mexico: a Study of Abuse Before and During Pregnancy. Am J Public Health. 2003; 93 (7): 1110-6.

11. Martin SL, Mackie L, Kupper LL, Buescher PA, Moracco KE. Physical abuse of women before, during, and after pregnancy. JAMA. 2011; 285 (12): 1581-4.

12. Pires MRM, Locatelli TZ, Rojas PFB, Lindner SR, Bolsoni CC, Coelho EBS. Prevalência e os fatores associados da violência psicológica contra gestantes em capital no sul do Brasil. Saúde Transform Social. 2017; 8 (1): 29-39.

13. Silva EP, Ludermir AB, Araújo TVBD, Valongueiro SA. Frequency and pattern ofintimate partner violence before, during and after pregnancy. Rev Saúde Pública. 2011; 45 (6): 1044-53.

14. Schraiber LB, D'Oliveira AF, Kiss LB, Durand J, Hanada H, Silva VN. Saúde da mulher, relações familiares e serviços de saúde do Sistema Único de Saúde (SUS) em duas capitais-Recife e São Paulo. São Paulo: Faculdade de Medicina da Universidade de São Paulo; 2007.

15. PNUD (Programa das Nações Unidas para o Desenvolvimento). Instituto de Pesquisa Econômica Aplicada, Fundação João Pinheiro. Base de dados: Atlas do desenvolvimento humano do Brasil. Perfil municipal: São Luis. São Luís; 2013.

16. Brasil DATASUS. Cobertura de consultas de pré-natal: São Luis, 2011. São Luís: DATASUS; 2011. 
17. World Health Organization. Estudo multi-países sobre saúde da mulher e violência doméstica. Geneva: WHO 2005 .

18. Schraiber LB, Latorre MRDO, França Júnior I, Segri NJ, D'Oliveira AFPL. Validity of the WHO VAW study instrument for estimating gender-based violence against women. Rev Saúde Pública. 2010; 44 (4): 658-66.

19. Ribeiro MR, Britto e Alves MT, Batista RF, Ribeiro CC, Schraiber LB, Barbieri MA, Bettiol H, Silva AAM Confirmatory factor analysis of the WHO Violence Against Women instrument in pregnant women: results from the Brisa prenatal cohort. PLoS One.2014; 9 (12): e115382.

20. Durand JG, Schraiber LB. Violência na gestação entre usuárias de serviços públicos de saúde da Grande São Paulo: prevalência e fatores associados. Rev Bras Epidemiol. 2007; 10: 310-22.

21. ABEP (Associação Brasileira de Empresas de Pesquisa). Critério de classificação econômica Brasil. Brasil; 2008.

22. Maldonato, MT. Psicologia da gravidez. 1 ed. Rio de Janeiro: Editora Jaguatirica Digital; 2013.
23. Durand JG, Schraiber LB, d'Oliveira AFPL. A vulnerabilidade à violência por parceiro íntimo na gestação: caminhos para seu enfrentamento. In: Lima FR, Santos C, organizadores. Violência Doméstica: vulnerabilidades e desafios na intervenção criminal e multidisciplinar. Rio de Janeiro: Lumen Juris; 2008; 1: 195-204.

24. Kiss LB, Schraiber LB. Temas médico-sociais e a intervenção em saúde: a violência contra mulheres no discurso dos profissionais. Ciênc Saúde Coletiva. 2011; 16 (3): 1943-52.

25. Hegarty K, O’Doherty L, Taft A, Chondros P, Brown S, Valpied J, Astbury J Taket A, Gold L, Feder G, Gunn J. Screening and counselling in the primary care setting for women who have experienced intimate partner violence (WEAVE): a cluster randomised controlled trial. Lancet. 2013; 382 (9888): 249-58.

26. Van Parys AS, Verhamme A, Temmerman M, Verstraelen $H$. Intimate partner violence and pregnancy: A systematic review of interventions. PloS One. 2014; 9 (1): e85084.

Received on December 17, 2019

Final version presented on February 28, 2020

Approved on March 30, 2020 